\section{TECHNICAL PERFORMANCE AND REFLECTION CAPACITY OF THE ANAESTHETIC CONSERVING DEVICE-A BENCH STUDY WITH ISOFLURANE AND SEVOFLURANE}

Andreas Meiser, $M D^{1}$, Martin Bellgardt, $M D^{1}$, Javier Belda, $M D, P h D^{2}$, Kerstin Röhm, MD, PhD ${ }^{3}$, Heinz Laubenthal, $M D, P h D^{1}$ and Clemens Sirtl, $M D^{1}$
Meiser A, Bellgardt M, Belda J, Röhm K, Laubenthal H, Sirtl C. Technical performance and reflection capacity of the anaesthetic conserving device-A bench study with isoflurane and sevoflurane.

J Clin Monit Comput 2009; 23:11-19

ABSTRACT. Objective. The anaesthetic conserving device (AnaConDa ${ }^{\circledR}$, Sedana Medical, Sundbyberg, Sweden) facilitates administration of isoflurane or sevoflurane by liquid infusion. An anaesthetic reflector inside the device conserves exhaled anaesthetic and re-supplies it during inspiration. In this bench study, we examined the influence of infusion rates and ventilatory settings on the resulting anaesthetic concentrations on patient $\left(\mathrm{C}_{\text {pat }}\right)$ and ventilator side of the reflector $\left(\mathrm{C}_{\text {loss }}\right)$ to describe its technical performance. Methods. A Puritan Bennett 840 ICU ventilator (Pleasanton, US), AnaConDa ${ }^{\circledR}$, and a test lung (3 1-chloroprene-bag) were assembled. Infusion rates (IR, $0.2-50 \mathrm{ml} \mathrm{h}^{-1}$ ), respiratory rates ( $\mathrm{RR}, 5-40$ breaths $\left.\min ^{-1}\right)$, and tidal volumes $\left(\mathrm{V}_{\mathrm{T}}, 0.3,0.5\right.$, and $\left.1.0 \mathrm{l}\right)$ were varied. $\mathrm{C}_{\text {pat }}$ was measured via a thin catheter in the middle of the 3 l-bag in steady state (online data storage and averaging over $>10 \mathrm{~min}$ ). $\mathrm{C}_{\text {loss }}$ was calculated from IR (to yield the volume of vapour per unit of time), and expired minute volume (in which the vapour is diluted) on the assumption that, in the steady state, input by liquid infusion equals output through the reflector. Results. At lower concentrations $\left(C_{\text {pat }}<1\right.$ vol\%) the ratio $\mathrm{C}_{\text {loss }} / \mathrm{C}_{\text {pat }}$ was constant $\left(R_{C}=0.096 \pm 0.012\right)$ for all combinations of IR, RR and $V_{T}$, both for isoflurane and sevoflurane. The device could efficiently reflect up to $10 \mathrm{ml}$ vapour per breath (e.g. 2 vol\% in 0.5 l). When exceeding this capacity, surplus vapour "spilled over" and $\mathrm{R}_{\mathrm{C}}$ markedly increased indicating decreased performance. Conclusions. The triple product minute volume times $\mathrm{R}_{\mathrm{C}}$ times $\mathrm{C}_{\text {pat }}$ describes anaesthetic losses through the reflector. It can easily be calculated as long as the $10 \mathrm{ml}$ reflection capacity is not exceeded and thus $\mathrm{R}_{\mathrm{C}}$ is constant. Increased minute ventilation necessitates increasing the IR to keep $\mathrm{C}_{\text {pat }}$ constant. When using large $\mathrm{V}_{\mathrm{T}}$ and high $\mathrm{C}_{\mathrm{pat}}$ "spill over" occurs. This effect offers some protection against an inadvertent overdose.

KEY WORDS. anaesthetic conserving device, isoflurane, sevoflurane, ICU, sedation.

List of abbreviations: $\mathrm{ACD}$ - anaesthetic conserving device; $\mathrm{Cl}$ - clearance; $\mathrm{C}_{\text {loss }}$ - mean anaesthetic concentration on the ventilator side of the reflector; $\mathrm{C}_{\text {pat }}$ - mean anaesthetic concentration in the test lung; CS - circle system; F - factor for calculating the volume of anaesthetic vapour from liquid anaesthetic; FGF - fresh gas flow; ICU - intensive care unit; $\mathrm{MV}$ - minute ventilation; IR - infusion pump rate (of the syringe pump); $\mathrm{R}_{\mathrm{C}}$ - ratio of the anaesthetic concentrations on both sides of the reflector $\left(\mathrm{C}_{\text {loss }} / \mathrm{C}_{\text {pat }}\right)$; RR - respiratory rate; $\mathrm{V}_{\mathrm{T}}$ - tidal volume; $\mathrm{V}^{\prime}$ delivered - volume of anaesthetic vapour delivered per unit of time; $\mathrm{V}^{\prime}$ loss - volume of

anaesthetic vapour lost through the reflector per unit of time 44791 Bochum, Germany. E-mail: andreas.meiser@rub.de

The data have been presented at the Annual Meeting of the 2007.

Ruhr-Universität Bochum, Gudrunt. Josef-Hosp Germany; ${ }^{2}$ Servicio de Anestesiología y Reanimación, Hospital Clínico Universitario, Valencia, Spain; ${ }^{3}$ Department of Anaesthesiology and Operative Intensive Care Medicine, Klinikum Ludwigshafen, Ludwigshafen, Germany.

Received 22 August 2008. Accepted for publication 11 December 2008.

Address correspondence to A. Meiser, Klinik für Anaesthesiologie, 


\section{INTRODUCTION}

The anaesthetic conserving device (ACD) AnaConDa ${ }^{\circledR}$ (Sedana Medical, Sundbyberg, Sweden) facilitates the administration of isoflurane or sevoflurane using conventional ventilators avoiding circle systems, vaporizers and soda lime. Its clinical use for anaesthesia has first been described by Enlund et al. [1], whereas Sackey et al. [2] reported its safe use for inhalational sedation in the intensive care unit (ICU). The device has been licensed in the European Union and Canada and is increasingly used for ICU sedation [3-5]. It is crucial to understand the principles of operation to become aware of pitfalls and achieve correct dosing of anaesthetics as the use of the ACD has little in common with the conventional vaporizer-circle system technique, the closed anaesthesia system or the dosing regimen of intravenous drugs. Therefore even for anaesthetists, the new method of application and its dependencies may be difficult to understand. When introducing the method into clinical practice, gas monitoring and some sort of gas scavenging must be available, and all staff involved must be properly trained. Some pitfalls and proper handling of the device have been described by our group [6].

A crucial ACD component is the anaesthetic reflector consisting of activated charcoal fibres. It conserves exhaled anaesthetic and re-supplies it during inspiration. This is similar to a heat moisture exchanger reflecting water vapour. However, in addition to reflecting, the ACD must also deliver anaesthetic. Therefore liquid anaesthetic is infused by a syringe pump into a porous rod called an evaporator. Evaporated anaesthetic in combination with reflected anaesthetic becomes the total inhaled anaesthetic.

It was the purpose of this bench study to determine the influence of both anaesthetic delivery and ventilatory settings on the concentrations of isoflurane and sevoflurane in a test lung. By comparing these with the corresponding concentrations on the ventilator side of the device we describe the technical performance of the reflector in a calculation model.

\section{METHODS AND MATERIALS}

\section{Experimental setup}

A Puritan Bennett 840 ICU ventilator (Pleasanton, California, USA) was set up and checked according to the manufacturer's instructions. In the performance verification test, the inaccuracy of volume measurement was determined to be below $10 \%$ for all calibration volumes $(0.025,0.2,0.6$ and 2.51$)$. The ventilator compensates volume measurement for body temperature pressure saturated conditions as well as for the compliance of hoses that was determined to be $2.27 \mathrm{ml} \mathrm{cm} \mathrm{H} \mathrm{H}^{-1}$ in the short self test. Leakage was negligible. An anaesthesia gas scavenging system with reservoir (AGS 33 300, Dräger Medical, Lübeck, Germany) was connected to the expiratory port of the ventilator to avoid contamination of the workplace.

Y-piece, ACD, a catheter mount with a bronchoscopy port and a 31 chloroprene bag for manual ventilation from an anaesthesia machine (Dräger Medical) were assembled in line, the latter serving as a test lung (Figure 1). Through the bronchoscopy port a thin catheter was inserted into the test lung for side stream gas monitoring with the monitor Vamos ${ }^{\circledR}$ (Dräger Medical) at a sampling rate of $0.151 \mathrm{~min}^{-1}$. The sample gas was returned to the patient side of the ACD through the port intended for gas sampling. All materials used were for single use and had never been in contact with volatile anaesthetics except the ventilator, the test lung and the gas monitor.

Liquid isoflurane or sevoflurane (Abbott Laboratories, Illinois, USA) were filled into a special syringe from the bottle using the appropriate adapter (Sedana Medical) in a separate room to avoid air pollution. The syringe (Sedana Medical), made of special material inert to the agents used, was fitted into a syringe pump before connecting it to the infusion line of the ACD. The syringe pump (Ivac ${ }^{\circledR}$, Cardinal Health-Alaris Products, Dublin, Ohio, USA) adjusted for Becton Dickinson Plastipak syringes with a high cut off pressure $(120 \mathrm{kPa})$ was installed on a constant

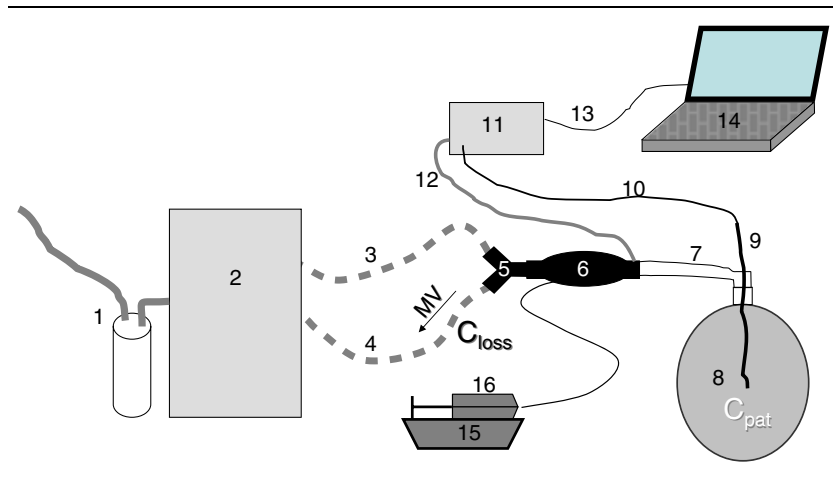

Fig. 1. Experimental setup. (1) Anaesthesia gas scavenging, (2) ICU ventilator, (3) inspiratory hose, (4) expiratory hose, (5) Y-piece, (6) anaesthetic conserving device, (7) catheter mount (with bronchoscopy port), (8) test lung (3 l chloroprene bag), (9) thin catheter, (10) gas sampling tube, (11) gas monitor, (12) redelivery of sample gas, (13) serial communication cable, (14) notebook computer for online data sampling, (15) syringe pump (16) syringe filled with liquid isoflurane or sevoflurane. $M V$ expiratory minute ventilation, carrying anaesthetic vapour through the anaesthetic reflector. $C_{\text {loss }}$ mean anaesthetic concentration in the gas expired through the anaesthetic reflector. $C_{\text {pat }}$ mean anaesthetic concentration inside the 31 bag under steady state conditions. 
level below the ACD to avoid gravity effects as described by Berton et al. [7] and our group [6].

Respiratory rates (RR), tidal volumes $\left(\mathrm{V}_{\mathrm{T}}\right)$ and infusion pump rates (IR) were varied. RR were $5,10,20$, and 40 breaths $\min ^{-1}, \mathrm{~V}_{\mathrm{T}} 0.3,0.5$, and 1.01 , and IR were $3.33,8.33,16.6,33.3,83.3,166.6$, and $833.3 \times 10^{-6}$ $1 \mathrm{~min}^{-1}\left(0.2,0.5,1.0,2.0,5.0,10.0\right.$, and $\left.50.0 \mathrm{ml} \mathrm{h}^{-1}\right)$. For experiments with $\mathrm{V}_{\mathrm{T}}$ of 0.3 and 1.01 , only a RR of 10 breaths $\min ^{-1}$ was used. We used constant inspiratory flow at $33 \%$ of total cycle time, no inspiratory hold, an oxygen concentration of $21 \mathrm{vol} \%$ and a positive end expiratory pressure of $3 \mathrm{~cm} \mathrm{H}_{2} \mathrm{O}$ to keep the test lung inflated.

\section{Calculation of $C_{\text {loss }}$}

In our bench model we calculated the mean anaesthetic concentration on the ventilator side of the reflector $\left(\mathrm{C}_{\text {loss }}\right)$. Under steady state conditions, confirmed by the stability of the concentration in the test lung, all anaesthetic delivered into the system per unit of time $\left(\mathrm{V}^{\prime}{ }_{\text {delivered }}\right)$ must escape the system. The anaesthetic vapour cannot diffuse through the test lung because chloroprene is impermeable to volatile anaesthetics. Air leaks have been excluded during the setup of the method. Therefore the only way for anaesthetic vapour to escape the system is through the anaesthetic reflector that will reflect most, but not all anaesthetic molecules. Anaesthetic molecules reaching the ventilator side of the reflector will be flushed away, diluted in the unsteady flow of the expired minute volume. $\mathrm{C}_{\text {loss }}$ can thus be calculated as follows:

$C_{\text {loss }}=\frac{V_{\text {delivered }}^{\prime}}{M V} \times 100=\frac{I R \times F}{R R \times V_{T}} \times 100 \quad(\mathrm{vol} \%)$

MV is the expired minute ventilation. $F$ is the factor for calculating anaesthetic vapour from liquid anaesthetic: Using the ideal gas law, Avogadro's law and the physical density of liquid isoflurane/sevoflurane, $\mathrm{F}$ can be calculated as 219.1 and $207.6 \mathrm{ml}$ vapour per $\mathrm{ml}$ liquid anaesthetic under body temperature pressure saturated conditions for isoflurane and sevoflurane, respectively.

\section{Measurement of $C_{\text {pat }}$}

The mean anaesthetic concentration in the middle of the test lung in steady state was called "patient concentration" $\left(\mathrm{C}_{\mathrm{pat}}\right)$. For all combinations of $\mathrm{RR}, \mathrm{V}_{\mathrm{T}}$ and $\mathrm{IR}$, both for isoflurane and for sevoflurane, experiments were performed twice: We expected $\mathrm{C}_{\mathrm{pat}}$ to be related to $\mathrm{C}_{\text {loss }}$. Therefore the experiments were arranged in such an order that $\mathrm{C}_{\text {loss}}$, calculated in advance, was first increasing, and then decreasing. This was done to reach the steady state earlier and to avoid a possible carry over effect by the volatile anaesthetic dissolving in and being released from the materials used. The measurements of $\mathrm{C}_{\text {pat }}$ from the inand decreasing series were finally averaged.

Gas measurements displayed to the second decimal place were stored online on a notebook computer once every second with the data sampling program Visia ${ }^{\circledR}$ provided by the gas monitor's manufacturer. For each experiment, data were sampled over a period of at least 30 min. The stability of the measured $\mathrm{C}_{\text {pat }}$ was confirmed visually by looking at a trend diagram. Only if a stable plateau was reached and maintained for at least $10 \mathrm{~min}$, data from this plateau were averaged. The gas monitor Vamos ${ }^{\circledR}$ calibrates itself automatically every $2 \mathrm{~h}$. We used two gas monitors of the same model and frequent exchanges did never result in different readings.

To describe the technical performance of the reflector, the ratio of $\mathrm{C}_{\text {loss }}$ to $\mathrm{C}_{\mathrm{pat}}$ was calculated $\left(R_{C}=C_{\text {loss }} / C_{\mathrm{pat}}\right)$. Data are presented as mean (SD). For comparison of $R_{C}$ for isoflurane and sevoflurane Student's $t$ test for paired samples was used.

\section{RESULTS}

Table 1 presents the measured values of $\mathrm{C}_{\text {pat }}$ and the ratio of the concentrations on both sides of the reflector $\left(R_{C}=C_{\text {loss }} / C_{\text {pat }}\right)$ at the different IR and ventilatory settings. Six settings yielding $\mathrm{C}_{\mathrm{pat}}$ outside the measurement range of the gas monitor $(4<0.1 \mathrm{vol} \%, 2>11 \mathrm{vol} \%)$ had to be discarded in the isoflurane and sevoflurane series (Table 1).

In Figure $2 \mathrm{a}$ and $\mathrm{b}$ the calculated $\mathrm{C}_{\text {loss }}$ is plotted against the measured $\mathrm{C}_{\mathrm{pat}}$ for isoflurane and sevoflurane, respectively. At lower concentrations $\left(\mathrm{C}_{\mathrm{pat}} \leq 1 \mathrm{vol} \%\right)$ there is a linear relationship between $\mathrm{C}_{\text {loss }}$ and $\mathrm{C}_{\mathrm{pat}}$ independent of the ventilatory settings. At higher concentrations all curves bend upwards. In the isoflurane (sevoflurane) diagram the curve for the large $\mathrm{V}_{\mathrm{T}}$ of 1.01 starts bending upwards between 0.77 and $1.42 \mathrm{vol} \%$ (0.69-1.31 vol\%), the curve for the small $\mathrm{V}_{\mathrm{T}}$ of 0.31 bends upwards between 2.30 and $4.44 \mathrm{vol} \%$ (2.17-4.06 vol\%). The four curves with the middle $\mathrm{V}_{\mathrm{T}}$ of $0.5 \mathrm{l}$, but with differing $\mathrm{RR}$, all bend upwards around 2 vol\%. Thus the RR shows little influence on the progression of the curves. Exponential regression lines do not give good fits because in the lower concentration range all curves seem exactly linear.

$\mathrm{R}_{\mathrm{C}}$ describes the slopes of the first linear parts of all curves. For these parts, until $\mathrm{R}_{\mathrm{C}}$ increases by more than $20 \%$ of the previous value (bold values Table 1 ), all values of $\mathrm{R}_{\mathrm{C}}$ were averaged to yield 0.097 (0.014) for isoflurane and $0.096(0.012)$ for sevoflurane. The small difference between the two is neither statistically nor clinically 


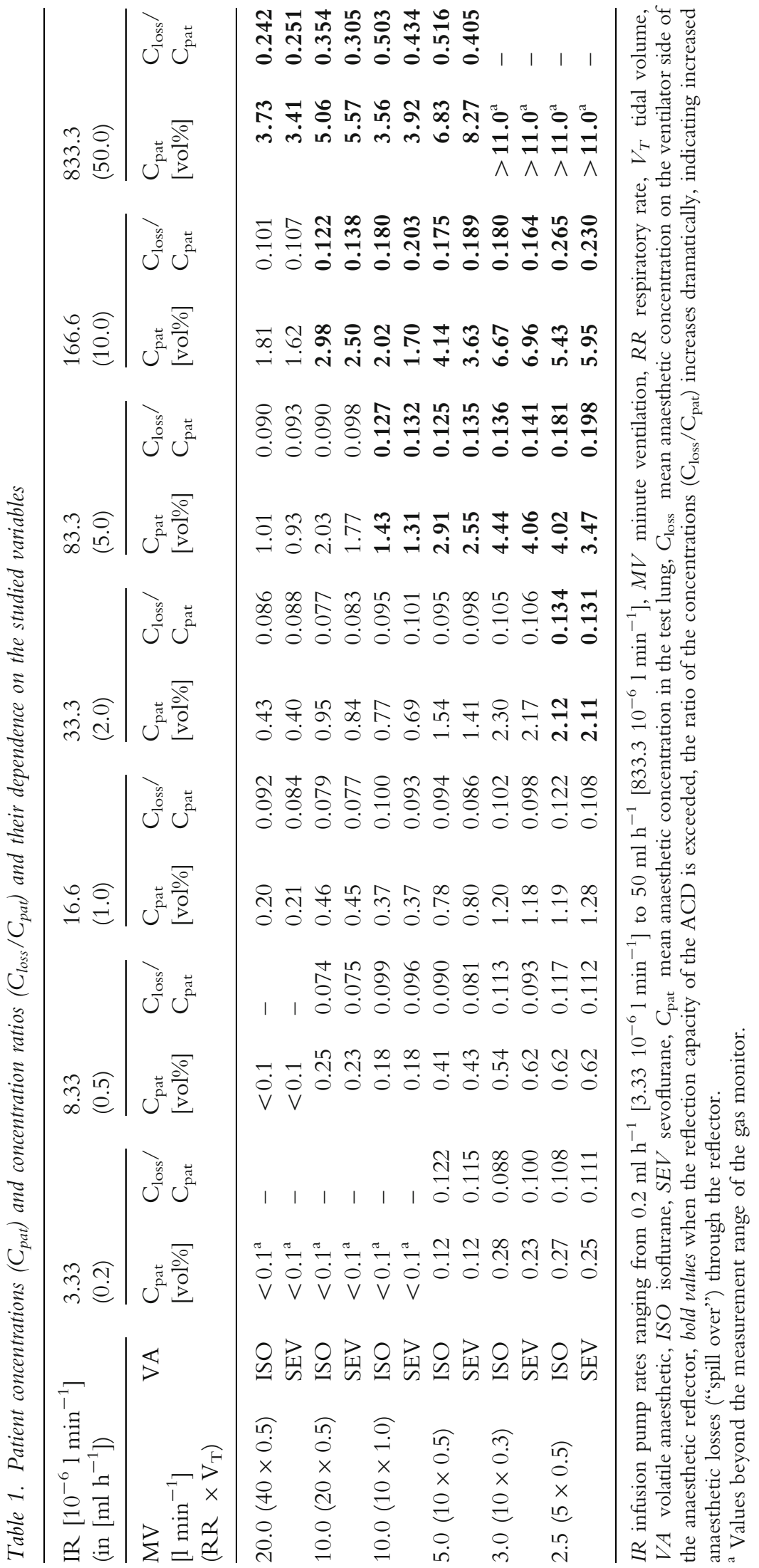




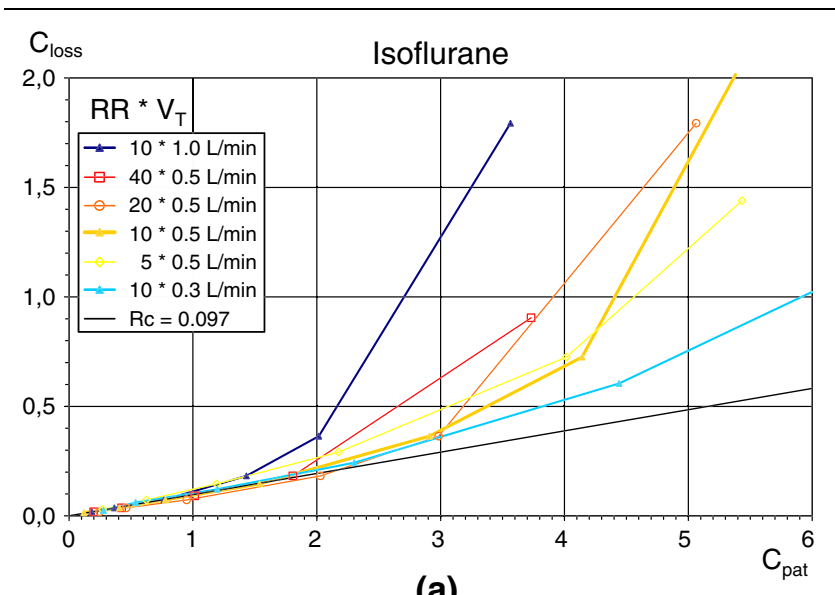

(a)

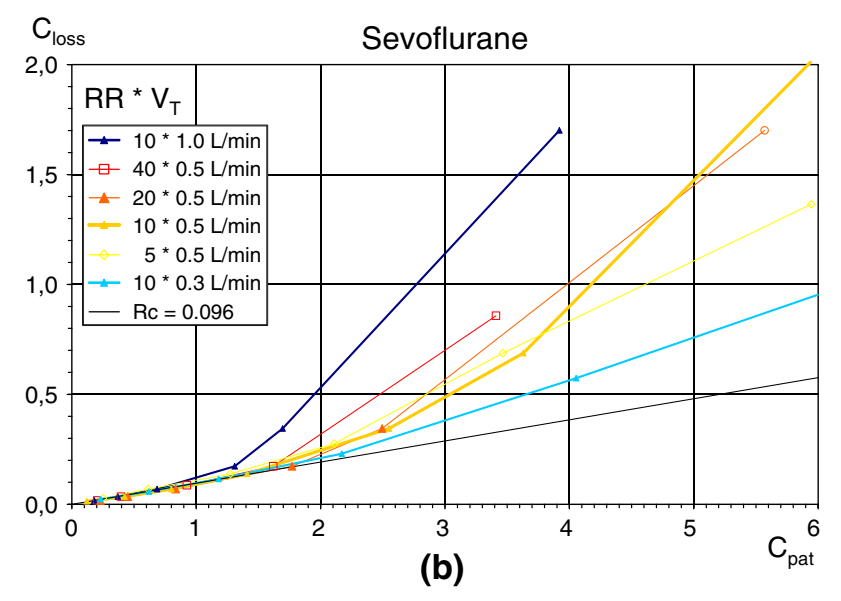

Fig. 2. (a) and (b) Characteristic curves of $A$ naConD $a^{\circledR}$ for isoflurane (a) and sevoflurane (b) with different ventilatory settings. The mean anaesthetic concentrations on the ventilator side of the anaesthetic reflector $\left(C_{\text {loss }}\right.$, [vol\%]) plotted against the mean anaesthetic concentrations in the test lung $\left(C_{\text {pat }},\left[\right.\right.$ vol\%]). $R R$ respiratory rates, $V_{T}$ tidal volumes. Each curve describes a different ventilatory setting, each point a different infusion pump rate. The straight line delineates a concentration ratio $C_{\text {loss }} / C_{\text {pat }}$ of 0.097 (isoflurane) and 0.096 (sevoflurane) respectively.

significant. Therefore the total average was calculated as 0.096 (0.012), or as a reciprocal value: one to 10.4.

\section{DISCUSSION}

It is the main finding of our study that the ratio of the anaesthetic concentrations on both sides of the anaesthetic reflector is constant with a value of $0.096(0.012)$ :

$R_{C}=\frac{C_{\text {loss }}}{C_{\text {pat }}}=0.096 \quad$ (dimensionless)

This technical performance is verifiable with different ventilatory settings, both for isoflurane and sevoflurane, and over the clinically used concentration range. In detail, constant concentrations measured for $\mathrm{C}_{\mathrm{pat}}$ were 10.4 times higher than $\mathrm{C}_{\text {loss }}$.

If we imagine that the anaesthetic reflector would not work at all, $\mathrm{C}_{\mathrm{pat}}$ would equal $\mathrm{C}_{\text {loss }}$ and the data points in Figure $2 \mathrm{a}$ and $\mathrm{b}$ would lie on the bisecting line. In $\mathrm{a}$ similar bench experiment, Berton et al. [7] removed the reflector from the device and the concentrations measured on the patient side $(0.1-0.4$ vol\%) were very close to our calculation for $\mathrm{C}_{\text {loss }}$ (Equation 1).

Another important finding of our study is that, when the volume of anaesthetic vapour expired in one breath exceeds $10 \mathrm{ml}\left(\mathrm{C}_{\mathrm{pat}} \times \mathrm{V}_{\mathrm{T}}\right.$; e.g. $1 \mathrm{vol} \% \times 1.01,2 \mathrm{vol} \% \times$ 0.51 or $3.33 \mathrm{vol} \% \times 0.31), \mathrm{C}_{\text {loss }}$ increases disproportionately. This may be interpreted as a "spill over": If during expiration the maximal capacity of the reflector is reached, no more anaesthetic molecules can be bound and they will be carried through the reflector and be lost for the patient. This "spill over effect" depends on the number of molecules contained in the expired $V_{T}$.

When using the ACD in clinical practice, one of the first questions arising is how to dose the anaesthetic to yield the desired "patient concentration" $\left(\mathrm{C}_{\mathrm{pat}}\right)$. By combining Equations 1 and 2, $\mathrm{C}_{\text {pat }}$ can easily be calculated as:

$C_{\text {pat }}=\frac{C_{\text {loss }}}{R_{C}}=\frac{I R}{R R \times V_{T}} \times \frac{F}{R_{C}} \times 100 \quad(\operatorname{vol} \%)$

For ICU sedation, usually $0.3-0.6 \mathrm{vol} \%$ isoflurane or $0.5-1.0 \mathrm{vol} \%$ sevoflurane are targeted. In this concentration range, $\mathrm{R}_{\mathrm{C}}$ will be constant. Therefore, in our bench model, $\mathrm{C}_{\mathrm{pat}}$ will be proportional to the infusion rate and inversely proportional to the minute volume. $\mathrm{RR}$ and $\mathrm{V}_{\mathrm{T}}$ have an equal influence.

In their bench study, Berton et al. [7] examined isoflurane $(F=219.1 \mathrm{ml}$ vapour per $\mathrm{ml}$ liquid anaesthetic) at an IR of $5 \mathrm{ml} \mathrm{h}^{-1}$, a rate commonly used in clinical practice. But because of the lack of patient uptake, this resulted in unusually high "patient concentrations" provoking spill over. According to Equation 3, an IR of $5 \mathrm{ml} \mathrm{h}^{-1}\left(83.3 \times 10^{-6} 1 \mathrm{~min}^{-1}\right)$, a RR of 12 breaths $\min ^{-1}$, and $\mathrm{a} \mathrm{V}_{\mathrm{T}}$ of 0.31 yields $5.2 \mathrm{vol} \%$. This means that one expired breath would contain $15.7 \mathrm{ml}$ anaesthetic vapour, which exceeds the capacity of the reflector. But the authors measured a concentration of only $3.4 \mathrm{vol} \%$ which corresponds to $10.2 \mathrm{ml}$ isoflurane vapour contained in one breath. When measuring in the range where spill over occurs, the reflector seems to behave irregularly and the authors were not able to construct a simple model for calculation of $\mathrm{C}_{\mathrm{pat}}$ such as the one presented here.

How can the ACD be compared to the classical circle system $(\mathrm{CS})$ ? During anaesthesia, anaesthetic vapour has to be delivered continuously to compensate firstly for patient 


\section{Comparing the performance}
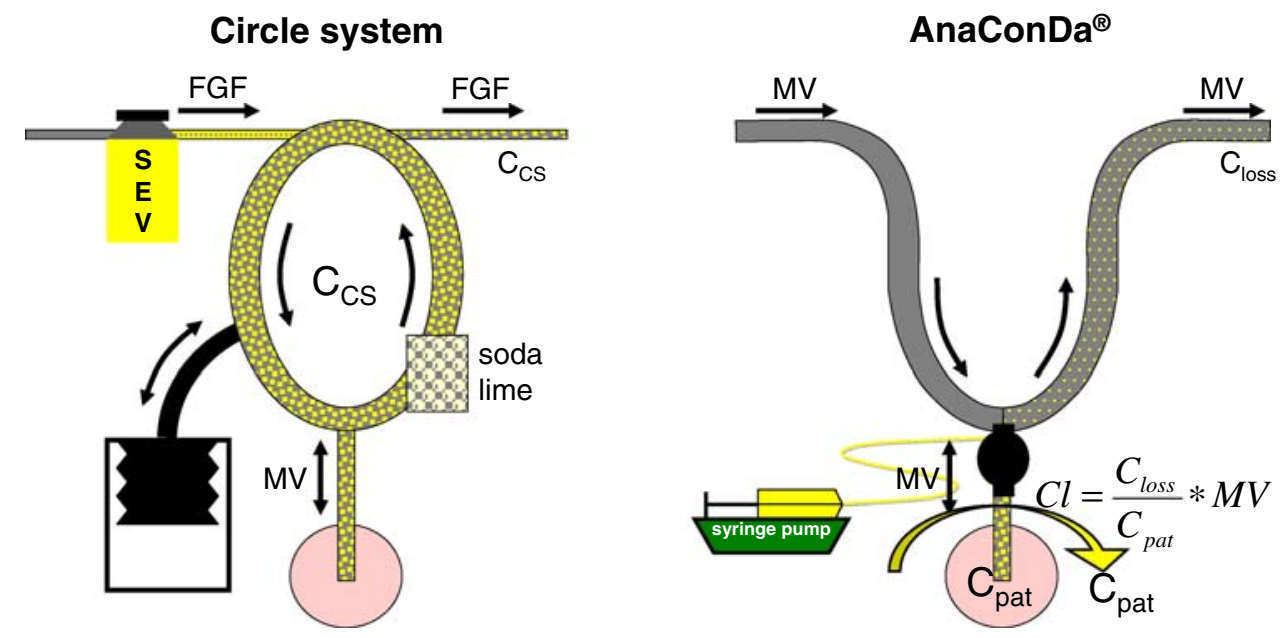

Fig. 3. Comparison of the circle system (CS) with the Anaesthetic Conserving Device (ACD). A classical anaesthesia machine consists of the fresh gas supply with the interposed vaporizer, the CS with soda lime, and a ventilator usually in form of a bag in bottle system. In the absence of patient uptake and leaks, the outflow from the CS equals the FGF and the anaesthetic concentrations in fresh gas, inspired and expired air will all be the same after wash in (C $\left.C_{C S}\right)$. Losses of anaesthetic vapour can be described as the product FGF times $C_{C S}$. With the $A C D$, the anaesthetic is delivered as a liquid via a syringe pump. $C_{\text {loss, }}$ the mean concentration on the ventilator side of the device, is 10.4 times lower than $C_{p a t}$. Vapour losses can be calculated as the product minute ventilation (MV) times $C_{\text {loss. }}$. Vapour losses can also be imagined to be carried away by a clearance flow flushing the patient side of the ACD (semicircular arrow). The clearance is a fraction $\left(C_{\text {loss }} / C_{\text {pat }}=0.097\right)$ of the minute volume. Vapour losses can be calculated as the product clearance times $C_{\text {pat }}$.

uptake, secondly for leaks of breathing gas, e.g. during tracheal suctioning or disconnections from the ventilator, and thirdly for losses that occur during the normal operating of the system. Let us assume there are no patient uptake and no leaks as in our bench test and look only at anaesthetic losses inherent to the respective systems $\left(\mathrm{V}_{\text {loss }}^{\prime}\right)$ :

In the CS, a specified fresh gas flow (FGF) enters the system on one side (Figure 3, left). In the absence of patient uptake and leaks, the outflow from the CS equals the FGF and the anaesthetic concentrations in fresh gas, inspired and expired air will all be the same after wash in $\left(\mathrm{C}_{\mathrm{CS}}\right)$. Losses of anaesthetic vapour can be described as ( $\mathrm{C}_{\mathrm{CS}}$ should be inserted as a dimensionless fraction):

$V_{\text {loss }, C S}^{\prime}=F G F \times C_{C S} \quad\left(1 \mathrm{~min}^{-1}\right)$

With the ACD anaesthetic losses can be described by the product $\mathrm{MV}$ times $\mathrm{C}_{\text {loss }}$ (Figure 3, right). In the lower concentration range we can replace $\mathrm{C}_{\text {loss }}$ by inserting Equation $2\left(\mathrm{C}_{\mathrm{pat}}\right.$ should be inserted as a dimensionless fraction):

$V_{\text {loss }, A C D}^{\prime}=M V \times R_{C} \times C_{p a t} \quad\left(1 \mathrm{~min}^{-1}\right)$

The product $\mathrm{MV}$ times $\mathrm{R}_{\mathrm{C}}$ corresponds to the FGF of a $\mathrm{CS}$ and both may be called clearance $(\mathrm{Cl})$ :

$C l_{A C D}=R_{C} \times M V=\frac{C_{\text {loss }}}{C_{p a t}} \times M V \quad\left(1 \mathrm{~min}^{-1}\right)$
This clearance of anaesthetic vapour through the reflector is in many respects analogous to the clearance of creatinine by the kidneys, which can be calculated as the ratio of the creatinine concentration in urine and plasma times the flow of urine. In the case of creatinine, the clearance corresponds to the glomerular filtration rate or the flow of primary urine. For most solutes, the clearance by the kidney does not correspond to any real flow, but can be imagined as the flow of an imaginary medium carrying the solute out of the body.

Whereas a good renal function is witnessed by a high clearance of solutes, a well performing ACD will be characterized by a low clearance of the anaesthetic vapour. Also in the case of the ACD the clearance may be imagined as a flow: If the ACD is performing well, $\mathrm{C}_{\text {loss }}$ will be much lower than $\mathrm{C}_{\mathrm{pat}}$ and the clearance will be a fraction $\left(R_{C}\right)$ of the minute ventilation. This fraction of the minute ventilation can be imagined to flush the system and carry the anaesthetic vapour away, comparable to the FGF flushing the CS.

There still remains one important difference between $\mathrm{CS}$ and ACD: Increasing the FGF will increase $\mathrm{V}^{\prime}$ loss. But at the same time the vaporizer will deliver a larger volume of vapour per unit of time, leaving the concentrations unchanged. With the ACD, when the MV, and thus the clearance flow, is increased, the syringe pump will not deliver any more anaesthetic automatically and therefore the IR has to be adjusted manually. 
We chose to calculate $\mathrm{C}_{\text {loss }}$ instead of measure it, as we expected $\mathrm{C}_{\text {loss }}$ to be ten times smaller than $\mathrm{C}_{\mathrm{pat}}$ and therefore out of the measurement range of our gas monitor in half of the experiments performed. Unlike $\mathrm{C}_{\mathrm{pat}}, \mathrm{C}_{\text {loss }}$ is not a stable concentration, but is fluctuating, and it would have been necessary to average $\mathrm{C}_{\text {loss }}$ over the expiratory flow. Measuring the expiratory flow and combining the two measurements would have increased the total error. On the other hand our calculation is straight forward. Even if the assumption that all materials on the patient side of the reflector (catheter mount, chassis of the AnaConDa ${ }^{\circledR}$ ) are gastight and that all anaesthetic delivered must be lost through the anaesthetic reflector, may not be absolutely right, these materials are used in clinical practice, and if anaesthetic agent is lost via these routes our calculations focussing on anaesthetic losses inherent to the ACD are valid.

We employed equipment commonly used in clinical practice. According to the manufacturer's specifications the accuracy of the gas monitor is $\pm 10 \%$. Measuring constant concentrations without tidal fluctuations and in the absence of water vapour should improve the accuracy. Two gas monitors were used and frequent exchanges did never result in different readings. In the calculation of $\mathrm{C}_{\text {loss}}$, delivery of $\mathrm{V}_{\mathrm{T}}$ by the ventilator may be afflicted with a maximum error of $\pm 10 \%$ as well, whereas $R R$ and IR may be considered exact. For calculation of $R_{C}$, with maximum errors of $\pm 10 \%$ in enumerator and denominator, total error can be estimated to be $\pm 20 \%$ at the most. But even if determination of $\mathrm{R}_{\mathrm{C}}$ may not be highly accurate, it is important to denote that $\mathrm{R}_{\mathrm{C}}$ is constant in the lower concentration range and dramatically increasing once the capacity of the reflector is exceeded.

It was the aim of our study to describe the functioning of the anaesthetic reflector as the more interesting and more innovative component of the new device. For several reasons we did not have a patient or experimental animal to take up the anaesthetic. For the calculation of $\mathrm{C}_{\text {loss }}$ it was necessary to look at steady state conditions without anaesthetic uptake as pointed out above. Our bench model allowed us to measure $\mathrm{C}_{\mathrm{pat}}$ as a stable concentration in the middle of the test lung. To avoid confusion we deliberately called that concentration 'patient concentration' and avoided the term 'endtidal'. In a patient study or in an animal model one would have to consider alveolar, dead space, and mixed portions of the expired tidal volume each with differing anaesthetic concentrations. Last not least our bench model allowed us to reduce the number of possible influencing and disturbing factors and to concentrate on IR, RR and $V_{T}$ with constant flows. We were also able to apply extreme conditions to get to the limits of the device, which would not have been so easily possible in a patient or in an animal model. Other factors that might influence the performance of the reflector are temperature, humidity and carbon dioxide. It is up to further studies to rule out or quantify their respective influence.

A number of clinical studies compared anaesthetic consumption with the ACD in a high flow system to conventional anaesthesia systems with specified FGFs. Enlund, Wiklund and Lambert observed a 40\% decrease in isoflurane consumption compared to a high flow coaxial Bain system [1]. The same group found the consumption of sevoflurane with the ACD to be similar to the one in a circle system with a FGF of $1.51 \mathrm{~min}^{-1}$ [8]. Tempia and colleagues came to the same conclusion: they found consumption of sevoflurane with the ACD in a half open breathing circuit to be $6.2 \mathrm{ml} \mathrm{h}^{-1}$. In the comparison groups using circle systems with FGFs of 1.0, 1.5, 3.0, and $6.01 \mathrm{~min}^{-1}$, the consumption was 5.2, 6.2, 13 and $24 \mathrm{ml} \mathrm{h}^{-1}$, respectively [9]. Assuming a MV of 5-10 $1 \mathrm{~min}^{-1}$, the above defined clearance would be $0.5-1.01 \mathrm{~min}^{-1}$. Therefore in theory the ACD should perform slightly better than it turned out in practice. Possible explanations to this fact might be the inclusion of the priming volume contained in infusion line and evaporator, which amounts to $1.3 \mathrm{ml}$ liquid anaesthetic, or possible spill over of volatile anaesthetic, when higher concentrations for anaesthesia are used.

Sackey et al. [10] reported an average consumption of only $2.1 \mathrm{ml} \mathrm{h}^{-1}$ isoflurane to maintain $\mathrm{C}_{\mathrm{pat}}$ at $0.5 \mathrm{vol} \%$ during long term ICU sedation. According to the authors, this was 4 times less compared to conventional high flow vaporizer systems. Assuming a minute ventilation of $101 \mathrm{~min}^{-1}$, the clearance would be $11 \mathrm{~min}^{-1}$ and $\mathrm{V}_{\text {loss }}^{\prime}$ can be calculated as $1.4 \mathrm{ml}$ liquid anaesthetic per hour (according to Equation 5 and after conversion to the appropriate units). The sample gas lost for gas monitoring accounts for another $0.2 \mathrm{ml} \mathrm{h}^{-1}$. So only $0.5 \mathrm{ml} \mathrm{h}^{-1}$ would be taken up by the patient, evaporate through the skin or escape through leaks, e.g. during tracheal suctioning.

Recently two studies evaluated the performance of pharmacokinetic models in patients in the operating theatre [11] and in the ICU [12]. This latter study evaluated the predictive performance of a simple pharmacokinetic model for the manually adjusted infusion of sevoflurane for use with the AnaConDa ${ }^{\circledR}$. The model calculated patient uptake based on a nine compartment model as well as losses through the ACD based on an equation that gives very close results and shows a high correlation with Equation 5. The study showed an excellent predictive performance of the model in $50 \mathrm{pa}-$ tients for duration of up to $6 \mathrm{~h}$.

We did not detect any differences between the two volatile anaesthetics examined, neither concerning $R_{C}$ 
(corresponding to the slopes of the first linear parts of the curves in Figure 2a, b), nor the range of high reflection performance (up to the points, when the curves start bending upwards). This is surprising considering the different physical characteristics of the two agents. As sevoflurane is less potent, higher concentrations are needed and thus spill over is more likely to occur. Our bench study is descriptive in nature and minor differences between the two volatile anaesthetics in the interaction with the ACD cannot be ruled out. To our knowledge, there is no published study examining differences in the two agents to be used with the AnaConDa ${ }^{\circledR}$.

Drug dosing not only according to body weight or body surface area but according to the MV is unusual for clinicians. When increasing the FGF, vaporizers will automatically deliver a larger volume of anaesthetic vapour as pointed out before. Only with low FGFs, when patient uptake has a major influence on the resulting concentrations, changes in FGF have to be met by changing the dial of the vaporizer [13]. Using the ACD however, the IR has to be adjusted, when the MV changes. But intensive care physicians are not used to changing the infusion rate of a drug when changing the settings of a ventilator. In addition, the MV may not only be changed by the doctor, but also by the patient when breathing spontaneously. An increase in $\mathrm{MV}$ will lower the concentration of the drug, which in turn might increase respiratory drive. As a consequence, upper and lower alarm limits for the MV should be set and the IR adjusted accordingly.

With higher concentrations the reflection capacity may be reached, especially when large tidal volumes are used. The "spill over" of anaesthetic molecules may indeed offer some protection against an inadvertent overdose: In clinical practice, it may happen that the IR of sevoflurane (isoflurane) erroneously is set at 50 instead of $5 \mathrm{ml} \mathrm{h}^{-1}$. With ventilatory settings of $10 \times 1.01 \mathrm{~min}^{-1}$, and according to our bench model (Equation 3), $\mathrm{C}_{\mathrm{pat}}$ instead of the intended $1.7 \mathrm{vol} \%(1.8 \mathrm{vol} \%)$ would increase to 17 vol\% (18 vol\%), if no spill over would occur and $R_{C}$ was constant over the whole concentration range. But in fact, $\mathrm{C}_{\mathrm{pat}}$ will only approach $3.9 \mathrm{vol} \%$ (3.6 vol\%, see Figure 2a, b; Table 1). If the same MV was applied with the settings $20 \times 0.51 \mathrm{~min}^{-1}$, again not 17 but $5.6 \mathrm{vol} \%$ (5.1 vol\%) will be reached. But if small $\mathrm{V}_{\mathrm{T}}$ are used, the spill over effect offers no protection and $\mathrm{C}_{\mathrm{pat}}$ will be above $11 \mathrm{vol} \%$ (upper limit of the measurement range of the gas monitor, see Table 1).

Therefore, a high performance of the reflector is not the only important thing. One could speculate about decreasing its capacity and by this narrow its range of high performance. If $\mathrm{C}_{\mathrm{pat}}$ increased, the clearance would increase earlier and more anaesthetic vapour would escape the system. This would further decrease the risk of over dosage, also when small tidal volumes are used. By reducing dead space, which in $A n a C o n D a{ }^{\circledR}$ is $100 \mathrm{ml}$, this as well would make the ACD more suitable for children [14].

\section{CONCLUSIONS}

In this bench study, in the steady state, and at lower concentrations ( $\leq 1 \mathrm{vol} \%$ ), the ratio of the concentrations on both sides of the anaesthetic reflector is constant at 0.096. This is true for isoflurane and sevoflurane and for different ventilatory settings. In other words, the anaesthetic concentration on the patient side is about ten times higher than the concentration on the ventilator side. Both concentrations are proportional to the infusion rate and inversely proportional to the respiratory rate and the tidal volume. Therefore in clinical practice, when the minute ventilation is increased (lowered), the infusion rate should also be increased (lowered) to keep the patient concentration constant.

If the volume of vapour expired within one breath exceeds $10 \mathrm{ml}\left(C_{\mathrm{pat}} \times V_{T}=0.01 \mathrm{l}\right.$; e.g. $1 \mathrm{vol} \% \times 1.01$, $2 \mathrm{vol} \% \times 0.51$, or $3.3 \mathrm{vol} \% \times 0.31$ ), the performance of the reflector decreases, as molecules exceeding the capacity of the reflector will be flushed away. This "spill over" effect may offer some protection against an inadvertent overdose.

In the lower concentration range, the clearance of anaesthetic vapour can be calculated as the ratio of the concentrations on both sides of the reflector $\left(\mathrm{R}_{\mathrm{C}}\right)$ times the minute volume. This clearance corresponds to a fresh gas flow in a circle system between 0.5 and $1.51 \mathrm{~min}^{-1}$. This has already been shown in clinical studies.

The study was carried out without third party funding. Abbott Laboratories and Sedana Medical bore the expenses for publishing this article with open access.

\section{REFERENCES}

1. Enlund M, Wiklund L, Lambert H. A new device to reduce the consumption of a halogenated anaesthetic agent. Anaesthesia 2001; 56: 429-432.

2. Sackey PV, Martling CR, Granath F, Radell PJ. Prolonged isoflurane sedation of intensive care unit patients with the Anesthetic Conserving Device. Crit Care Med 2004; 32: 2241-2246.

3. Thomson H, Harper NJ, Parkes A. Use of the AnaConDa anaesthetic delivery system to treat life-threatening asthma. Anaesthesia 2007; 62: 295-296. 
4. Jung C, Granados M, Marsol P, Murat I, Gall O. Use of sevoflurane sedation by the $\operatorname{AnaConDa}((\mathrm{R}))$ device as an adjunct to extubation in a pediatric burn patient. Burns 2008; 34: 136-138.

5. Nickel EA, Benken I, Bartels U, Voelckel WG, Quintel M. AnaCoDa as last resort treatment. Case report of a chronic obstructive pulmonary disease. Anaesthesist 2007; 56: 587-591.

6. Meiser A, Laubenthal H. Inhalational anaesthetics in the ICU: theory and practice of inhalational sedation in the ICU, economics, risk-benefit. Best Pract Res Clin Anaesthesiol 2005; 19: 523-538.

7. Berton J, Sargentini C, Nguyen J, Belii A, Beydon L. AnaConDa reflection filter: bench and patient evaluation of safety and volatile anesthetic conservation. Anesth Analg 2007; 104: 130-134.

8. Enlund M, Lambert H, Wiklund L. The sevoflurane saving capacity of a new anaesthetic agent conserving device compared with a low flow circle system. Acta Anaesthesiol Scand 2002; 46: 506-511.

9. Tempia A, Olivei M, Calza E, et al. The anesthetic conserving device compared with conventional circle system used under different flow conditions for inhaled anesthesia. Anesth Analg 2003; 96: 1056-1061.

10. Sackey PV, Martling CR, Nise G, Radell PJ. Ambient isoflurane pollution and isoflurane consumption during intensive care unit sedation with the Anesthetic Conserving Device. Crit Care Med 2005; 33: 585-590.

11. Enlund M, Kietzmann D, Bouillon T, Zuchner K, Meineke I. Population pharmacokinetics of sevoflurane in conjunction with the AnaConDa: toward target-controlled infusion of volatiles into the breathing system. Acta Anaesthesiol Scand 2008; 52: 553-560.

12. Belda J, Soro M, Badenes R, et al. The Predictive performance of a pharmacokinetic model for manually adjusted infusion of liquid sevoflurane for use with the Anaesthetic-Conserving Device (AnaConDa). A clinical study. Anesth Analg 2008; 106: 1207-1214.

13. Baum J. Low flow anaesthesia (2nd ed.). Butterworth-Heineman: Stuttgart, New York, 2001.

14. Sackey PV, Martling CR, Radell PJ. Three cases of PICU sedation with isoflurane delivered by the 'AnaConDa'. Paediatr Anaesth 2005; 15: 879-885. 